
Evgeniy Davydov, Georgiy Pariiskii, Iryna Gaponova,
Tatyana Pokholok and Gennady Zaikov

\title{
POLYMERS IN POLLUTED ATMOSPHERE. FREE RADICAL AND ION-RADICAL CONVERSIONS INITIATED BY NITROGEN OXIDES
}

\author{
Emanuel Institute of Biochemical physics, Russian Academy of Sciences \\ 4 Kosygin str., 119334 Moscow, Russia \\ pgb@sky.chph.ras.ru
}

Received: November 22, 2007

\begin{abstract}
Nitric oxide, nitrogen dioxide, nitrogen trioxide as well as dimers of nitrogen dioxide are reactive initiators of radical transformations of macromolecules and modifying reactants for polymers. Features of the initiation mechanism determining the composition of molecular and radical products in polymers under the action of nitrogen oxides are discussed.
\end{abstract}

Keywords: nitrogen oxide, polymer, reaction, radical, EPR spectrum.

\section{Introduction}

Nitrogen oxides play an important role in various chemical processes taking place in an atmosphere and affect an environment [1-4]. These compounds in increasing amount are ejected into atmosphere by industrial plants and motor transport in creating thus a large ecological problem. Investigations of kinetics and mechanism of reactions initiated by nitrogen oxides are important for determination of various organic compounds stability of vegetative and animal origin as well as synthetic polymeric materials in conditions of polluted atmosphere. On the other hand, nitrogen oxides find a wide application for synthetic chemistry [5-7] and may by used for chemical modification of polymers, in particular for preparation of spin-labelled macromolecules $[8,9]$. The generation of spin labels takes place in this case as a consecutive process including formation and conversion of specific intermediate molecular products and active free radicals. It is necessary to note essential advantages of such a way of obtaining spin labels not requiring application of complex synthetic methods based on reactions of stable aminoxyl radicals with functional groups of macroradicals [10]. If the polymers are capable of reacting with nitrogen oxides, the formation of stable radicals takes place spontaneously or by thermolysis of molecular products of nitration [11, 12].

Nitrogen oxides of the three types: $\mathrm{NO}, \mathrm{NO}_{2}, \mathrm{NO}_{3}$ are the most important for reactions with various organic compounds and polymers. All of them represent free radicals with different reactivity [13]. In the present review the features of the mechanism of these oxides reactions and also dimers of $\mathrm{NO}_{2}$ with a number of polymers and low-molecular compounds are considered. The special attention is given to the analysis of the stable nitrogencontaining radicals structure and kinetic features of their formation. On the basis of the results of the analysis, the conclusions on the mechanism of primary reactions of initiation and intermediate stages of complex radical processes under the action of nitrogen oxides are given. The principles of the nitrogen oxides use for grafting spin labels upon various polymers are considered.

\section{Results and Discussion}

\subsection{Interaction of nitric oxide with products of photolysis and radiolysis of polymers}

The NO radical is least reactive among three examined nitrogen oxides. It is not capable of abstracting hydrogen atoms even from the least strong tertiary or allyl $\mathrm{C}-\mathrm{H}$ bonds; the strength of $\mathrm{H}-\mathrm{NO}$ bond amounts is only $205 \mathrm{~kJ} \cdot \mathrm{mol}^{-1}[14]$. Nitric oxide cannot join the isolated double bonds of the alkenes [15] and initiate radical reactions in that way. For NO, the recombination with free radicals with formation of nitroso compounds is a characteristic process. The structure of stable nitrogen-containing radicals formed from nitroso compounds (spin traps) in the subsequent reactions can give information on the mechanism of radical processes taking place in the reacting system.

Let's consider such an opportunity by the example of polymethylmethacrylate (PMMA). During photolysis of PMMA in atmosphere of NO by unfiltered light of a mercury lamp at $298 \mathrm{~K}$, the formation of acylalkylaminoxyl radicals $\mathrm{R}_{1} \mathrm{~N}(\mathrm{O}) \mathrm{C}(=\mathrm{O}) \mathrm{OR}_{2}$ was observed with typical parameters of anisotropic triplet EPR spectrum in a solid phase:

$$
A_{\mathrm{II}}^{\mathrm{N}}=2.1 \pm 0.1 \mathrm{mT} g_{\mathrm{II}}=2.0027 \pm 0.0005 \text { [16] (Fig. 1a). }
$$




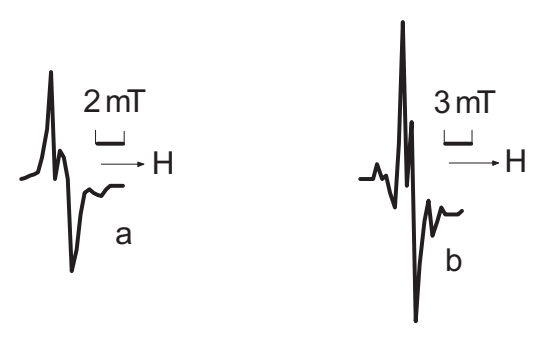

Fig. 1. ESR spectra of PMMA after photolysis (a) and radiolysis (b) in atmosphere of NO at $298 \mathrm{~K}$

The occurrence of acylalkylaminoxyl radicals is the evidence of eliminating of methoxycarbonyl radicals in the course of the polymer photolysis:

PMMA $\stackrel{h v}{\longrightarrow} \sim\left(\mathrm{CH}_{3}\right) \mathrm{C}\left(\mathrm{COOCH}_{3}\right) \mathrm{CH}_{2} \mathrm{C}^{\prime}\left(\mathrm{CH}_{3}\right) \sim\left(\mathrm{R}^{\circ}\right)+{ }^{\circ} \mathrm{COOCH}_{3}$

The subsequent reaction with participation of $\mathrm{NO}$ gives acylalkylaminoxyl radicals:

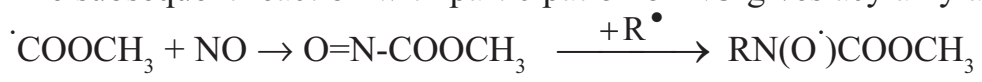

With the help of NO, it was possible to establish the nature of intermediate short-lived radicals in a photochemical process using EPR spectra of stable nitrogen-containing radicals.

Radiolysis of PMMA in the presence of $\mathrm{NO}$ at room temperature in addition to acylalkylaminoxyl radicals gives iminoxyl macroradicals (Fig. 1b) with the following parameters of the ESR spectrum: $\quad A_{\mathrm{II}}^{\mathrm{N}}=4.5 \pm 0.1 \mathrm{mT}$, $g_{\perp}=2.0054 \pm 0.0005[16]$. As for photolysis, $\gamma$-irradiation of PMMA is accompanied by the detachment of ester groups and the formation of acylalkylaminoxyl radicals similarly to the reaction (1). But radiolysis causes an increase in the contribution of hydrogen abstraction from methylene groups of the main chain with the $A_{\perp}^{\mathrm{N}}=2.4 \pm 0.1 \mathrm{mT} ; \quad g_{\mathrm{II}}=2.0025 \pm 0.0005$, formation of corresponding macroradicals:

PMMA $\stackrel{\gamma}{\longrightarrow} \sim\left(\mathrm{CH}_{3}\right) \mathrm{C}\left(\mathrm{COOCH}_{3}\right) \mathrm{C}^{\cdot} \mathrm{H}\left(\mathrm{CH}_{3}\right) \mathrm{C}\left(\mathrm{COOCH}_{3}\right) \sim\left(R_{1}^{\bullet}\right)$

These macroradicals by recombination with $\mathrm{NO}$ are converted into nitroso compounds:

$$
R_{1}^{\bullet}+\mathrm{NO} \rightarrow \sim\left(\mathrm{CH}_{3}\right) \mathrm{C}\left(\mathrm{COOCH}_{3}\right) \mathrm{CH}(\mathrm{NO})\left(\mathrm{CH}_{3}\right) \mathrm{C}\left(\mathrm{COOCH}_{3}\right) \sim\left(R_{1} \mathrm{NO}\right)
$$

Nitroso compounds having $\alpha$-hydrogen atom are easily transformed into oximes which in reaction with active methoxycarbonyl radicals form registered stable iminoxyl radicals:

$$
\begin{array}{r}
R_{1}^{\bullet} \mathrm{NO} \rightarrow \sim\left(\mathrm{CH}_{3}\right) \mathrm{C}\left(\mathrm{COOCH}_{3}\right) \mathrm{C}(=\mathrm{NOH})\left(\mathrm{CH}_{3}\right) \mathrm{C}\left(\mathrm{COOCH}_{3}\right) \sim \stackrel{{ }^{\circ} \mathrm{COOCH}_{3}}{\longrightarrow} \\
\sim\left(\mathrm{CH}_{3}\right) \mathrm{C}\left(\mathrm{COOCH}_{3}\right) \mathrm{C}\left(=\mathrm{NO}^{\circ}\right)\left(\mathrm{CH}_{3}\right) \mathrm{C}\left(\mathrm{COOCH}_{3}\right) \sim+\mathrm{HCOOCH}_{3}
\end{array}
$$

Thus the composition of stable nitrogen-containing radicals reflects primary reactions taking place in PMMA under the action of light and $\gamma$-radiation.

The application of nitric oxide enables to prepare spin-labelled macromolecules in chemically inert and insoluble polymers, for example in polyperfluoroalkanes.
As was shown in the work [16], the radiolysis of polytetrafluoroethylene (PTFE) oriented films and copolymer of tetrafluoroethylene with hexafluoropropylene initiates reactions with the formation of iminoxyl macroradical according to the following scheme:

$$
\begin{aligned}
& \mathrm{PTFE} \stackrel{\gamma}{\longrightarrow} \sim \mathrm{CF}_{2} \mathrm{C}^{\cdot} \mathrm{FCF}_{2} \sim+\mathrm{NO} \rightarrow \sim \stackrel{\gamma}{\longrightarrow} \mathrm{CF}_{2} \mathrm{CF}(\mathrm{NO}) \mathrm{CF}_{2} \sim \stackrel{\gamma}{\longrightarrow} \\
& \sim \mathrm{CF}_{2} \mathrm{C}(\mathrm{NO}) \mathrm{CF}_{2} \sim \rightarrow \sim \mathrm{CF}_{2} \mathrm{C}(=\mathrm{NO}) \mathrm{CF}_{2} \sim \\
& \sim \mathrm{CF}_{2} \mathrm{CF}\left(\mathrm{CF}_{3}\right) \mathrm{CF}_{2} \sim \stackrel{\gamma, \mathrm{NO}}{\longrightarrow} \sim \mathrm{CF}_{2} \mathrm{CF}\left(\mathrm{CF}_{2} \mathrm{NO}^{2} \mathrm{CF}_{2} \sim \stackrel{\gamma}{\longrightarrow}\right. \\
& \sim \mathrm{CF}_{2} \mathrm{CF}\left(\mathrm{C}^{\mathrm{F}} \mathrm{FNO}\right) \mathrm{CF}_{2} \sim \rightarrow \sim \mathrm{CF}_{2} \mathrm{CF}\left(\mathrm{CF}=\mathrm{NO}^{\circ}\right) \mathrm{CF}_{2} \sim
\end{aligned}
$$

Aminoxyl radicals in polyperfluoroalkanes are not formed under these conditions. However, if one carries out $\gamma$-irradiation in the air, middle and end peroxide macroradicals appear with conversion into fluoroaminoxyl macroradicals $\sim \mathrm{CF}_{2} \mathrm{CF}\left(\mathrm{NO}^{\circ}\right) \mathrm{CF}_{2} \sim$ by the subsequent exposure to NO. Their ESR spectra in oriented films are 
quintet of triplets (Fig. 2) with the parameters:

$$
\begin{aligned}
& A_{\mathrm{II}}^{\mathrm{N}}=0.46 \mathrm{mT}, \quad A_{\mathrm{II}}^{\mathrm{F}}=1.11 \mathrm{mT}, \quad g_{\mathrm{II}}=2.006 ; \\
& A_{\perp}^{\mathrm{N}}=1.12 \mathrm{mT}, \quad A_{\perp}^{\mathrm{F}}=1.61 \mathrm{mT} \text { and } g_{\perp}=2.0071 .
\end{aligned}
$$

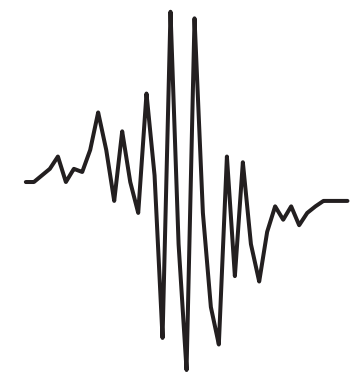

\section{$\stackrel{1 \mathrm{mT}}{\longrightarrow} \mathrm{H}$}

Fig. 2. ESR spectrum of PFTE films previously $\gamma$-irradiated on air after subsequent exposure to $\mathrm{NO}$

The following mechanism of the aminoxyl radical formation in these conditions is proposed [17]:

$\sim \mathrm{CF}_{2} \mathrm{CF}_{2} \mathrm{CF} \mathrm{CF}_{2} \sim \rightarrow \mathrm{CF}_{2}+\mathrm{CF}_{2}=\mathrm{CFCF}_{2} \sim$

The end alkyl radical is oxidized into the end peroxide radical:

$\sim \mathrm{CF}_{2}+\mathrm{O}_{2} \rightarrow \sim \mathrm{CF}_{2} \mathrm{OO}$

In $\mathrm{NO}$ atmosphere, the end peroxide radicals are converted as follows:

$\sim \mathrm{CF}_{2} \mathrm{CF}_{2} \mathrm{OO}+\mathrm{NO} \rightarrow \sim \mathrm{CF}_{2} \mathrm{CF}_{2} \mathrm{O}^{\circ}+\mathrm{NO}_{2}$

$\sim \mathrm{CF}_{2} \mathrm{CF}_{2} \mathrm{O}^{\circ}+\mathrm{NO} \sim \leftrightarrow \mathrm{CF}_{2} \mathrm{CF}_{2} \mathrm{ONO}$

$\sim \mathrm{CF}_{2} \mathrm{CF}_{2} \mathrm{O} \rightarrow \sim \mathrm{CF}_{2}+\mathrm{COF}_{2}$

$\sim \mathrm{CF}_{2}+\mathrm{NO} \rightarrow \sim \mathrm{CF}_{2} \mathrm{NO}$

$\sim \mathrm{CF}_{2} \mathrm{NO}+\mathrm{CF}_{2}=\mathrm{CFCF}_{2} \sim \stackrel{\mathrm{NO}}{\longrightarrow}$

$\sim \mathrm{CF}_{2} \mathrm{~N}\left(\mathrm{O}^{\circ}\right) \mathrm{CF}_{2} \mathrm{CF}(\mathrm{NO}) \mathrm{CF}_{2} \sim$

Thus, spin-labelled macromolecules of fluoroalkyl polymers can be prepared by using postradiating free radical reactions in $\mathrm{NO}$ atmosphere.

\subsection{Radical reactions initiated by nitrogen trioxide}

The radicals $\mathrm{NO}_{3}$ play a significant role in chemical processes occurring in the top layers of atmosphere [18]. These radicals are formed in reaction of nitrogen dioxide with ozone:

$$
\mathrm{NO}_{2}+\mathrm{O}_{3} \rightarrow \mathrm{NO}_{3}+\mathrm{O}_{2}
$$

Under the action of daylight, nitrogen trioxide is consumed with liberation of atomic oxygen:

$$
\mathrm{NO}_{3} \stackrel{\mathrm{h} v}{\longrightarrow} \mathrm{NO}_{2}+\mathrm{O}
$$

Its disappearance occurs in reaction with nitrogen dioxide at night:

$$
\mathrm{NO}_{3}+\mathrm{NO}_{2} \rightarrow \mathrm{N}_{2} \mathrm{O}_{5}
$$

The $\mathrm{NO}_{3}$ radicals are characterized by high reactivity in reactions with various organic compounds [18-22]. Typical reactions of these radicals are abstraction of hydrogen atoms from $\mathrm{C}-\mathrm{H}$ and addition to double bonds. Furthermore, nitrogen trioxide can appear as an oxidizer of organic compounds. Along with these reactions, the radicals $\mathrm{NO}_{3}$ are decomposed in thermal and photochemical processes. The thermal decomposition of nitrogen trioxide generated by pulse radiolysis of concentrated water solutions of a nitric acid takes place with high rate $\left(k_{208 \mathrm{~K}}=8 \cdot 10^{3}, \mathrm{~s}^{-1}\right)$ [23]:

$$
\mathrm{NO}_{3} \stackrel{k T}{\longrightarrow} \mathrm{NO}_{2}+\mathrm{O}
$$

The radicals $\mathrm{NO}_{3}$ have three intensive absorption bands in visible region of an optical spectrum with $\lambda_{\max }=$ $600,640,675 \mathrm{~nm}$, and in UV region at 340-360 nm [18, 19, 23-27]. Under the action of light, $\mathrm{NO}_{3}$ dissociates by two mechanisms including formation of $\mathrm{NO}_{2}$ and atomic oxygen similarly to reaction (18) or nitrogen oxide and molecular oxygen [1]:

$$
\mathrm{NO}_{3} \rightarrow \mathrm{NO}+\mathrm{O}_{2}
$$

The efficiency of the $\mathrm{NO}_{3}$ conversion by one or either mechanisms is determined by spectral composition of light. Above $570 \mathrm{~nm}, \mathrm{NO}_{3}$ decomposes into $\mathrm{NO}$ and $\mathrm{O}_{2}$ with the very high $(\sim 1)$ quantum yield; the basic products of the photolysis are $\mathrm{NO}_{2}+\mathrm{O}$ below $570 \mathrm{~nm}$. One of the most widespread ways of $\mathrm{NO}_{3}$ generation is the photolysis of $\mathrm{Ce}$ (IV) nitrates in particular ceric ammonium nitrate $(\mathrm{CAN})\left(\mathrm{NH}_{4}\right)_{2} \mathrm{Ce}\left(\mathrm{NO}_{3}\right)_{6}$. The absorption spectrum of CAN has a wide and intensive band with the maximum at $305 \mathrm{~nm}\left(\varepsilon=58901 \cdot \mathrm{mol}^{-1} \cdot \mathrm{cm}^{-1}\right)$ which is conditioned by an electron transfer to $\mathrm{Ce}^{4+}$ from nitrate anion. Under the action of light in the given spectral region there is a photoreduction of CAN [26, 27]:

$$
\mathrm{Ce}^{4+} \mathrm{NO}_{3}^{-} \stackrel{\mathrm{h} v}{\longrightarrow} \mathrm{Ce}^{3+}+\mathrm{NO}_{3}
$$

Thus, the CAN photolysis gives different active radical particles: $\mathrm{NO}, \mathrm{NO}_{2}, \mathrm{NO}_{3}$ and atomic oxygen. Application of light of various spectral composition allows to generate these particles in different ratio. Atomic oxygen being a very active reactant [14] interacts with $\mathrm{C}-\mathrm{H}$ bonds of organic compounds. Macroradicals formed by the action of atoms $\mathrm{O}$ on polymers can be converted in the presence of NO into stable aminoxyl radicals. The use of these processes for the purposes of chemical modification of polymers is considered by the example of polyvinylpyrrolidone (PVP) in the work [28].

The formation of $\mathrm{NO}_{2}$ by reactions (20) and (18) in the process of CAN photolysis is confirmed by ESR spectra obtained at $77 \mathrm{~K}$. The spectrum at the initial stage of irradiation of PVP with CAN $\left(0.05-0.2 \mathrm{~mol} \cdot \mathrm{kg}^{-1}\right)$ by light with $\lambda>280 \mathrm{~nm}$ is shown in Fig. 3a. 


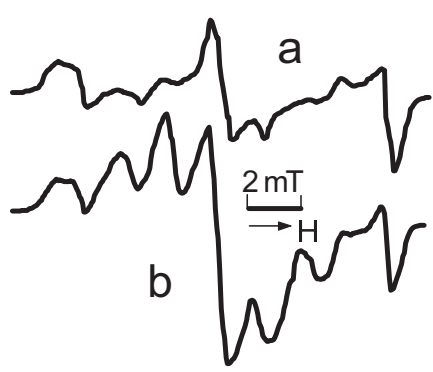

Fig. 3. ESR spectra PVP with CAN irradiated by light with $\lambda>280 \mathrm{~nm}$ at $77 \mathrm{~K}$ during $2 \mathrm{~min}$ (a) and $60 \mathrm{~min}(\mathrm{~b})$

It represents basically a triplet signal with obviously expressed anisotropy of $\gamma$-factor and hyperfine structure. Essentially, it is in accordance with a spectrum of $\mathrm{NO}_{2}$ radicals trapped in ice at $77 \mathrm{~K}$ [29]. The analysis of Fig. 3a has given much the same values of $A$ and $g$-tensors: $A_{x x}=3.31 \mathrm{mT}, A_{y y}=4.93 \mathrm{mT}, A_{z z}=5.31 \mathrm{mT}$, and

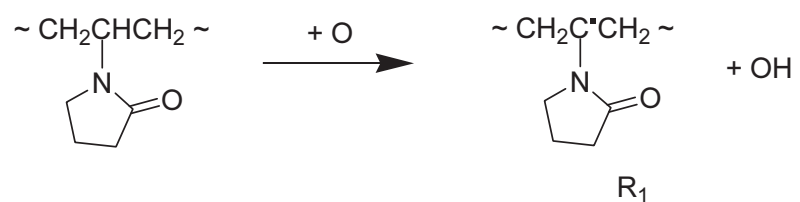

$g_{x x}=2.0066, \quad g_{y y}=1.9929, \quad g_{z z}=2.0024$. During the further irradiation, additional lines appeared on a background of the $\mathrm{NO}_{2}$ signal, which belongs most likely to radicals of PVP (Fig. 1b) formed as a result of the following reaction:

The radicals $R_{1}$ are stabilized only at low temperatures $(77 \mathrm{~K})$. Photolysis of samples at $298 \mathrm{~K}$ by the same light results in the production of stable dialkylaminoxyl radicals characterized by anisotropic ESR triplet spectrum with parameters of $g_{\mathrm{II}}=3.18 \mathrm{mT}$ and

$A_{\mathrm{II}}^{\mathrm{N}}=2.0024$ (Fig. 4). The cross-linkage of PVP macromolecules takes place under these conditions with the formation of a gel-fraction as a result of the recombination of macroradicals $\mathrm{R}_{1}$ with nitric oxide:

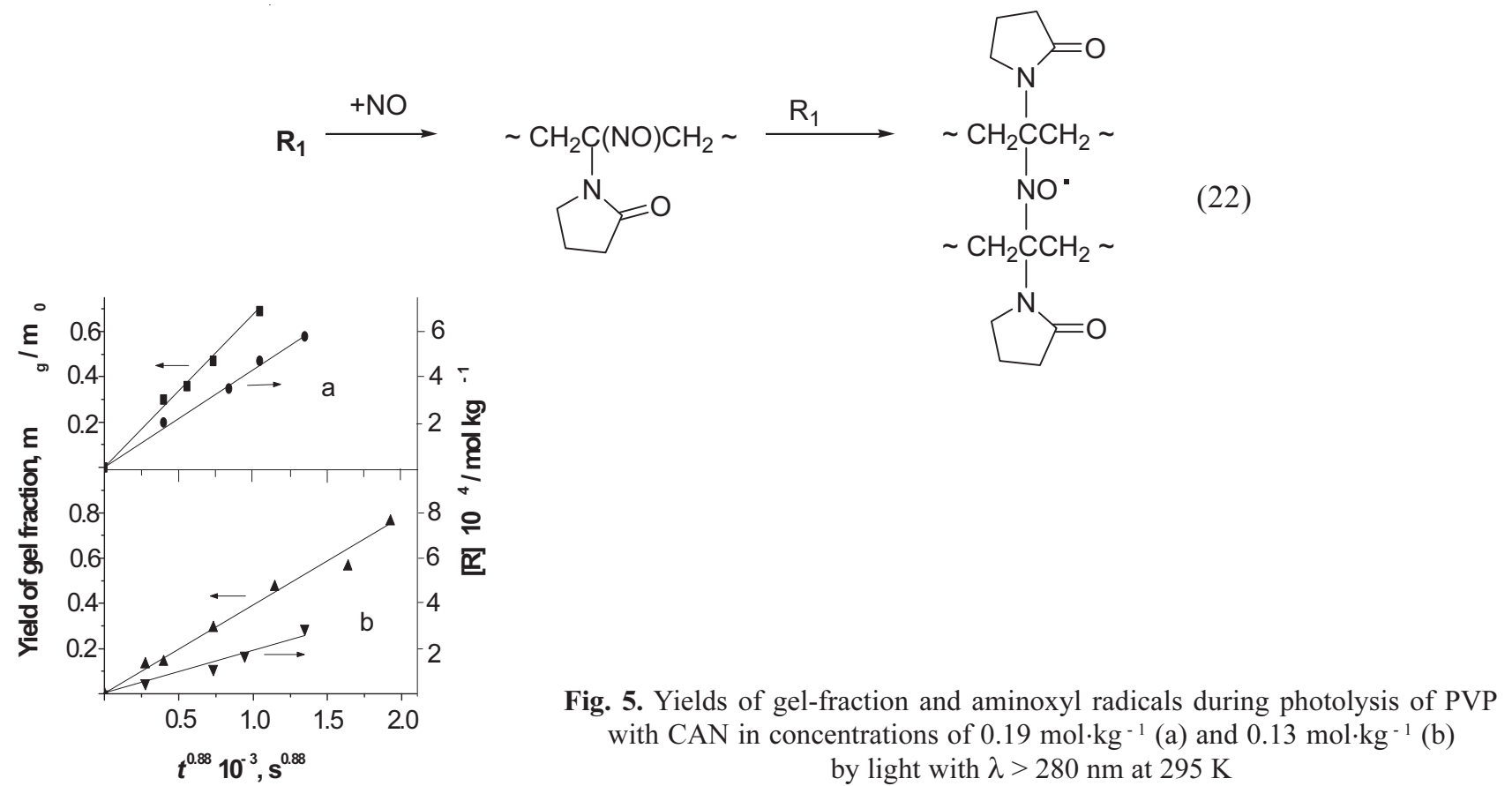


Both processes of gel and aminoxyl radical formation are in direct correlation during photolysis of PVP with CAN. The linear dependencies shown in Fig. 5a and $b$ indicate that fact. Formally, the kinetics of any product $N$ formation with monotonously decreasing rate can be represented by the equation:

$N=a t^{n}$

where $a$ and $n$ are empirical parameters, and $0<n<1$. One can see from Fig. 5a and b, kinetic curves are linearized in the same co-ordinates of equation (23). The value of parameter $n=0.88$ is obtained from analysis of kinetic dependencies by a least-squares method. Such regularity confirms the mechanism (22), according to which the aminoxyl radicals are formed with participation of nitric oxide and can be considered as crosslinks for macromolecules. If crosslinking were to occur in some other way, for example, by direct recombination of radicals

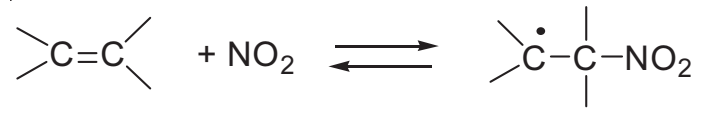

$\mathrm{R}_{1}$, aminoxyl radicals and gel accumulations would not be correlated as follows from Fig. 5a and b. Such a simple method of crosslinking PVP can be applied for obtaining hydrogels used as specific sorbents [30].

\subsection{Free radical and ion-radical reactions under the action of nitrogen dioxide and its dimers}

Nitrogen dioxide effectively reacts with various lowand high-molecular organic compounds [5-7, 31]. However, it must be emphasized that $\mathrm{NO}_{2}$ is a free radical of moderate reactivity, and the ONO-H bond strength [14] makes up $320 \mathrm{~kJ} \mathrm{~mol}^{-1}$. Therefore, radicals $\mathrm{NO}_{2}$ are capable of initiating free radical reactions by abstraction of hydrogen atoms from the least strong, for example, allyl $\mathrm{C}-\mathrm{H}$ bonds or addition to double $\mathrm{C}=\mathrm{C}$ bonds $[32,33]$ :

This process causes further radical conversions of olefins with formation of dinitro compounds and nitro nitrites:<smiles>CCC(C)[N+](=O)[O-]</smiles><smiles>CC(C)(O[N+](=O)[O-])C(C)(C)[N+](=O)[O-]</smiles>

From Jellinek's data [31], butyl rubber destroys under the action of $\mathrm{NO}_{2}$ :

$$
\sim \mathrm{C}\left(\mathrm{CH}_{3}\right)=\mathrm{CH} \sim \quad+\mathrm{NO}_{2} \rightleftarrows \sim \dot{\mathrm{C}}\left(\mathrm{CH}_{3}\right)-\mathrm{CH}\left(\mathrm{NO}_{2}\right) \sim \quad \longrightarrow \text { destruction }
$$

As a consequence of primary reactions of nitrogen dioxide radicals with the isolated double bonds, stable aminoxyl radicals can be generated. Such transformations are characteristic for rubbers.

\subsubsection{Preparation of spin- labelled rubbers}

The possibility of obtaining spin-labelled rubbers by interaction of their solutions in the inert solvents with the mixture of nitrogen dioxide and oxygen has been demonstrated in the work [34]. Such rubbers can be prepared simply and rapidly by reactions of block polymeric samples with gaseous $\mathrm{NO}_{2}$ [35]. The experiments were carried out on 1,4-cis-polyisoprene (PI) and copolymer of ethylene, propylene and dicyclopentadiene. The samples had the form of cylinders of 1.5 $\mathrm{cm}$ height and $0.4 \mathrm{~cm}$ in diameter. On exposure of these polymers to $\mathrm{NO}_{2}\left(10^{-5}-2.3 \cdot 10^{-3} \mathrm{~mol} \cdot \mathrm{l}^{-1}\right)$ at $295 \mathrm{~K}$, identical ESR spectra were registered. The spectra represent an anisotropic triplet with parameters which are typical for dialkylaminoxyl radicals with $A_{\mathrm{II}}^{\mathrm{N}}=3.1 \mathrm{mT}$ and $g_{\mathrm{II}}=$ $=2.0028 \pm 0.0005$ (Fig. 6a). The spectra with such parameters testify that the correlation time of rotational mobility $t_{\mathrm{c}}$ at the given temperature exceeds $10^{-9} \mathrm{~s}$. At increasing temperature up to $373 \mathrm{~K}$, the isotropic triplet signal with $g=1.53 \pm 0.03 \mathrm{mT}$ and $=2.0057 \pm$ \pm 0.0005 was observed (Fig. 6b), that is caused by essential decreasing correlation time $\left(5 \cdot 10^{-11}<t_{\mathrm{c}}<10^{-9} \mathrm{~s}\right)$. The change of $t_{\mathrm{c}}$ with temperature (Fig. 7) is described by the relation $t_{\mathrm{c}=} t_{0} \exp (E / R T)$, where $\log t_{0}=-14.2$, and $E$ is the activation energy of rotational diffusion $\left(34.7 \mathrm{~kJ} \cdot \mathrm{mol}^{-1}\right)$.

The scheme of the aminoxyl radical formation includes three basic stages: generation of macroradicals in reaction of $\mathrm{NO}_{2}$ with rubbers; synthesis of macromolecular nitroso compounds and spin trapping of macroradicals by nitroso compounds.

As can be seen from this scheme, the accumulation of aminoxyl radicals should be accompanied by crosslinkage of macromolecules. The presence of oxygen inhibits the aminoxyl accumulation as a result of conversions of primary nitroalkyl and allyl macroradicals into peroxide radicals. 


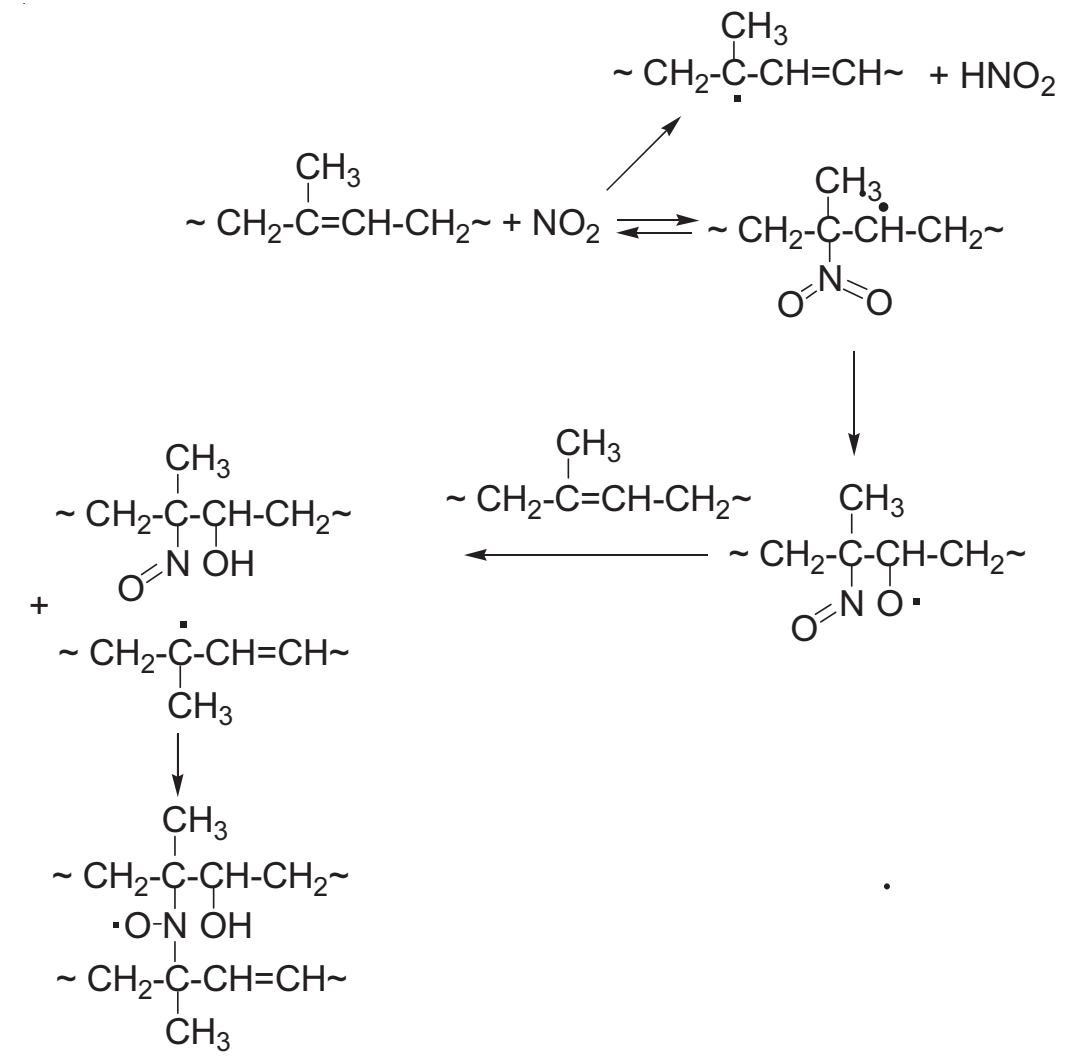

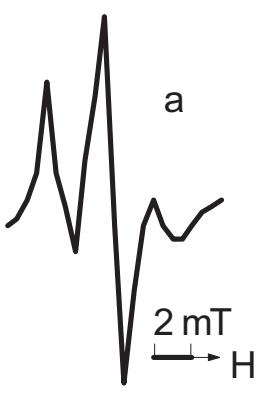

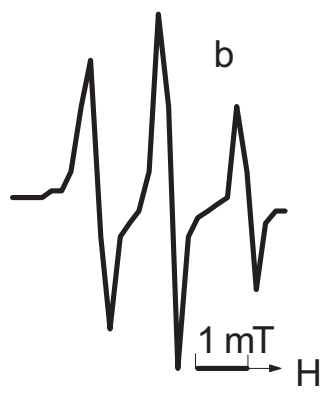

Fig. 6. ESR spectra of PI after exposure to $\mathrm{NO}_{2}$ at $295 \mathrm{~K}$ (a) and $373 \mathrm{~K}(\mathrm{~b})$

\subsection{Mechanism of initiation of radical reactions by nitrogen dioxide dimers}

As noted above, nitrogen dioxide can initiate free radical reactions in compounds containing weakest $\mathrm{C}-\mathrm{H}$ bonds or double $\mathrm{C}=\mathrm{C}$ bonds. However, the effective formation of stable nitrogen-containing radicals was also observed in aromatic polyamidoimides, polycaproamide, polyvinylpyrrolidone (PVP) [8] and also aromatic polyamide (AP) [12]. These facts allow considering other

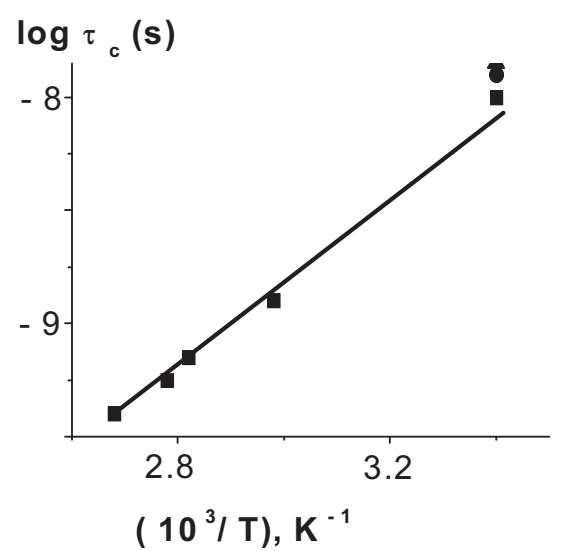

Fig. 7. Temperature dependence of the correlation time of rotational diffusion of PI macromolecules measured using aminoxyl radicals as spin labels

probable mechanisms of the radical processes initiation. The fact is that the basic radical products of interaction of nitrogen dioxide with polymers containing amide groups are iminoxyl and acylalkylaminoxyl radicals which are produced from oximes and acylnitroso compounds $[8$, 12]. The occurrence of these predecessors of stable radicals is in turn connected with the nitric oxide formation.

In this connection, a participation of $\mathrm{NO}_{2}$ dimeric forms in radical initiation should be considered. The main dimers of $\mathrm{NO}_{2}$ are planar nitrogen tetroxide $\mathrm{O}_{2} \mathrm{~N}-\mathrm{NO}_{2}(\mathrm{PD})$ 
and nitrosyl nitrate $\mathrm{ONONO}_{2}(\mathrm{NN})$. Ab initio calculations [33] show that these dimers are formed with the most probability in $\mathrm{NO}_{2}$ atmosphere; the form of nitrosyl peroxynitrite ONOONO is too unstable to be considered as an efficient participant of reactions, however it can play the role of an intermediate compound at oxidation of nitric oxide by oxygen [36]. As NN has strong oxidative properties [37], the generation of radicals can take place by an electron transfer from donor functional groups with the formation of intermediate radical cations [9, 38]:

$$
\mathrm{RH}+\mathrm{ONONO}_{2} \rightarrow\left[\mathrm{RH}^{+}\left(\mathrm{NO} \cdot \mathrm{ONO}_{2}^{-}\right)\right] \rightarrow \mathrm{R}+\mathrm{NO}+\mathrm{H}^{+}+\mathrm{ONO}_{2}^{-}
$$

The recombination of radicals with nitric oxide forms nitroso compounds that undergo isomerisation into oximes [39] to produce iminoxyl radicals in the reaction with $\mathrm{NO}_{2}$ :

$$
>\mathrm{C}=\mathrm{NOH}+\mathrm{NO}_{2} \rightarrow>\mathrm{C}=\mathrm{NO}+\mathrm{HNO}_{3}
$$

The tertiary nitroso compounds are effective spin traps and the source of stable aminoxyl radicals:

$$
\mathrm{R}_{1} \mathrm{~N}=\mathrm{O}+\mathrm{R}_{2} \cdot \mathrm{R}_{1}\left(\mathrm{R}_{2}\right) \mathrm{N}-\mathrm{O}
$$

Thus the mechanism involving reactions (29-31) could formally explain an appearance of stable radicals in the polymers not containing specific chemical bonds reacting with $\mathrm{NO}_{2}$ mono radicals. However, there are

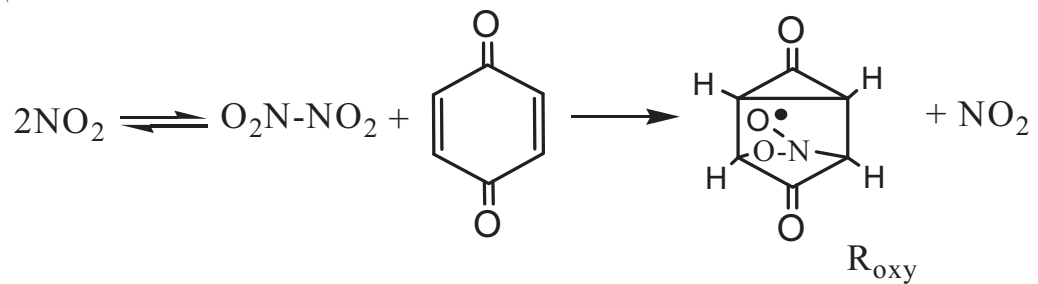

The triplet ESR spectrum of radicals $\mathrm{R}_{\text {oxy }}$ in $\mathrm{Q}$ (Fig. 8) has parameters: $A^{\mathrm{N}}=2.82 \mathrm{mT}$ and $g=2.0053$.

The mechanism (33) is confirmed by kinetic data. The relationships between the initial rates of the $\mathrm{R}$ accumulation and partial pressures of $\mathrm{NO}_{2}$ and $\mathrm{N}_{2} \mathrm{O}_{4}$

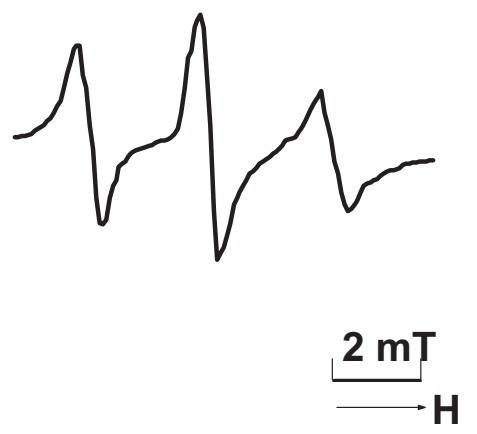

Fig. 8. ESR spectrum of $R_{\text {oxy }}$ obtained by the exposure of Q to nitrogen dioxide at $295 \mathrm{~K}$ certain obstacles connected with energetic properties of $\mathrm{NO}_{2}$ dimers [33] for realizing such mechanism; the energy of syn- and anti forms of NN exceeds that of PD respectively 29.8 and $18.4 \mathrm{KJ} \cdot \mathrm{mol}^{-1}$; that is the equilibrium

$$
\mathrm{O}_{2} \mathrm{~N}-\mathrm{NO}_{2} \rightleftharpoons 2 \mathrm{NO}_{2} \rightleftharpoons \mathrm{ONONO}_{2}
$$

should be shifted to PD in a gas phase.

The diamagnetic PD is capable of generating nitrogen-containing radicals in a specific reaction with the system of the conjugated double bonds of $p$ - quinones (Q) [40]. On exposure of $Q$ to nitrogen dioxide, the formation of radicals of oxyaminoxyl type $\left(\mathrm{R}_{\text {oxy }}\right)$ [41] takes place by the following scheme:

$$
\mathrm{R}_{\text {oxy }}
$$

calculated from known equilibrium constants are shown in Fig. 9, from which it is clear that the experimental values of the initial rates depend linearly on the partial pressures of $\mathrm{N}_{2} \mathrm{O}_{4}$ and not of $\mathrm{NO}_{2}$. Thus, both forms of $\mathrm{NO}_{2}$ dimers can be active.

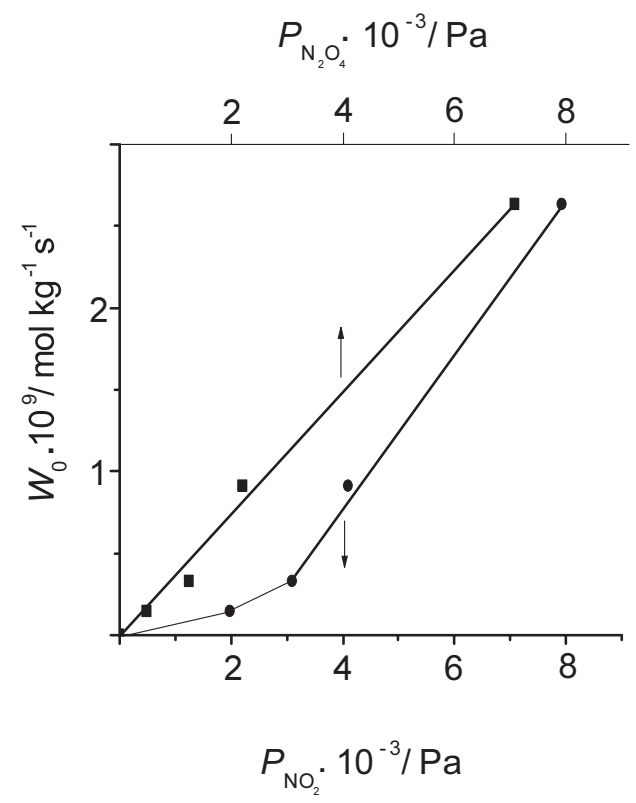

Fig. 9. Dependence of initial rates of accumulation of $\mathrm{R}_{\text {oxy }}$ at $295 \mathrm{~K}$ on partial pressures of $\mathrm{NO}_{2}$ and $\mathrm{N}_{2} \mathrm{O}_{4}$ 


\subsection{Experimental confirmations of ion-radical mechanism of polymers nitrosation}

Registration of radical cations by the ESR method in the presence of nitrogen dioxide could provide direct experimental evidence that the initiation proceeds via $\mathrm{NN}$ by scheme (29). However, because of high reactivity and fast decomposition [42], these particles are difficult to detect by this method. Nevertheless, the formation of radical cations can be revealed indirectly in the act of their decomposition with detachment of a proton. The possibility of detecting radical cations during their decomposition accompanied by the proton emission has been demonstrated by the example of interaction of nitrogen dioxide with poly(2-vinylpyridine) (PVPyr). Pyridine is known to be capable of accepting protons to yield pyridinium cations. Hence, if protons are formed during decomposition of radical cations by reaction (29), they can be detected easily from IR spectra typical to pyridinium cations. Note that pyridine conversions can be nitrated only under quite severe conditions. For example, N-nitropyridinium nitrate was obtained only when pyridine was treated with $\mathrm{NO}_{2}$ - ozone mixture in an inert solvent [43]. However, nitrogen dioxide efficiently interacts with PVPyr.

Fig. 10 represents the IR spectra of the original PVPyr films and the same films exposed to $\mathrm{NO}_{2}$ $\left(5 \cdot 10^{-4} \mathrm{~mol} \cdot \mathrm{l}^{-1}\right)$ [38]. After $90 \mathrm{~min}$ exposure at room temperature, two intense bands were observed in the spectrum at 2400-2600 and $2200 \mathrm{~cm}^{-1}$ corresponding to the stretching vibrations of $\mathrm{NH}^{+}$pyridinium cations [44]. The bands at $1600-1430 \mathrm{~cm}^{-1}$, attributed to the stretching vibrations of $\mathrm{C}=\mathrm{C}$ and $\mathrm{C}=\mathrm{N}$ bonds of pyridine rings, are present in the initial spectrum of PVPyr [44]. During exposure to $\mathrm{NO}_{2}$, a band at $1650 \mathrm{~cm}^{-1}$ corresponding to the stretching vibrations of $\mathrm{C}=\mathrm{N}^{+}$bonds arises in the spectrum simultaneously with the bands at $2400-2600$ and $2200 \mathrm{~cm}^{-1}$. This process may be schematically depicted as follows [38]:

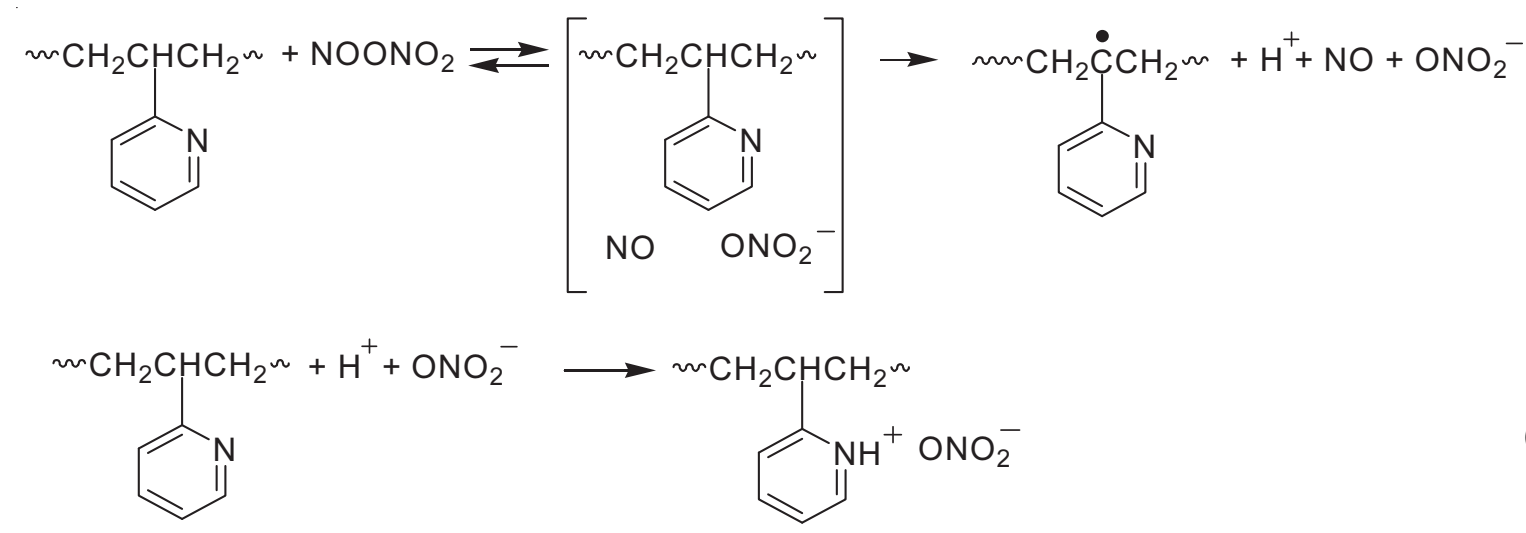

Thus pyridine rings fix an occurrence of radical cations as a result of an electron transfer to NN, and in doing so the ion-radical mechanism (29) is experimentally confirmed. It is possible to believe that such oxidative mechanism of generating radicals is characteristic for compounds with the ionization potential providing electron transfer from donor groups of molecules to NN. This regularity can be followed from examples of thermal and photochemical nitration of aromatic compounds under the action of nitrogen dioxide. According to UV spectroscopy data, NN can form chargetransfer complexes with methylbenzenes $[45,46]$. For the complexes, a bathochromic shift in the corresponding absorption bands was observed with an increase in number of methyl substituents in the benzene ring. This shift correlates with a decrease in the ionization potential from 8.44 to $7.85 \mathrm{eV}$ passing from $p$-xylene to hexamethylbenzene.

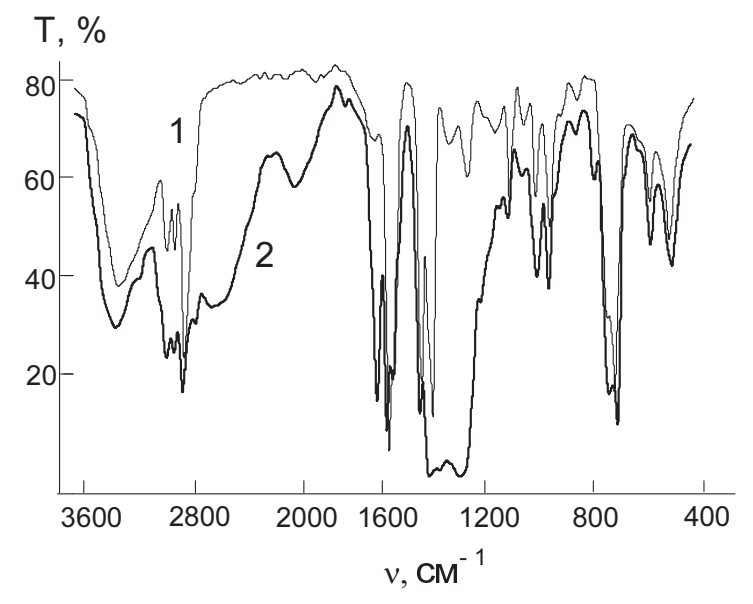

Fig. 10. IR spectra of the original PVPyr films (1) and after exposure to $\mathrm{NO}_{2}(2)$ 
2.6. Effect of nitrogen dioxide on aliphatic and aromatic polyamides

Oxidative ion-radical mechanism of conversions induced by NN explains high activity of aliphatic polyamides and AP to nitrogen dioxide as well as the nature of stable radicals and molecular products of nitration. Amide groups can serve as donor electrons in polyamides. The regularities of aliphatic transformations in particular polycaproamide $[8,9]$ may be described by the following scheme:

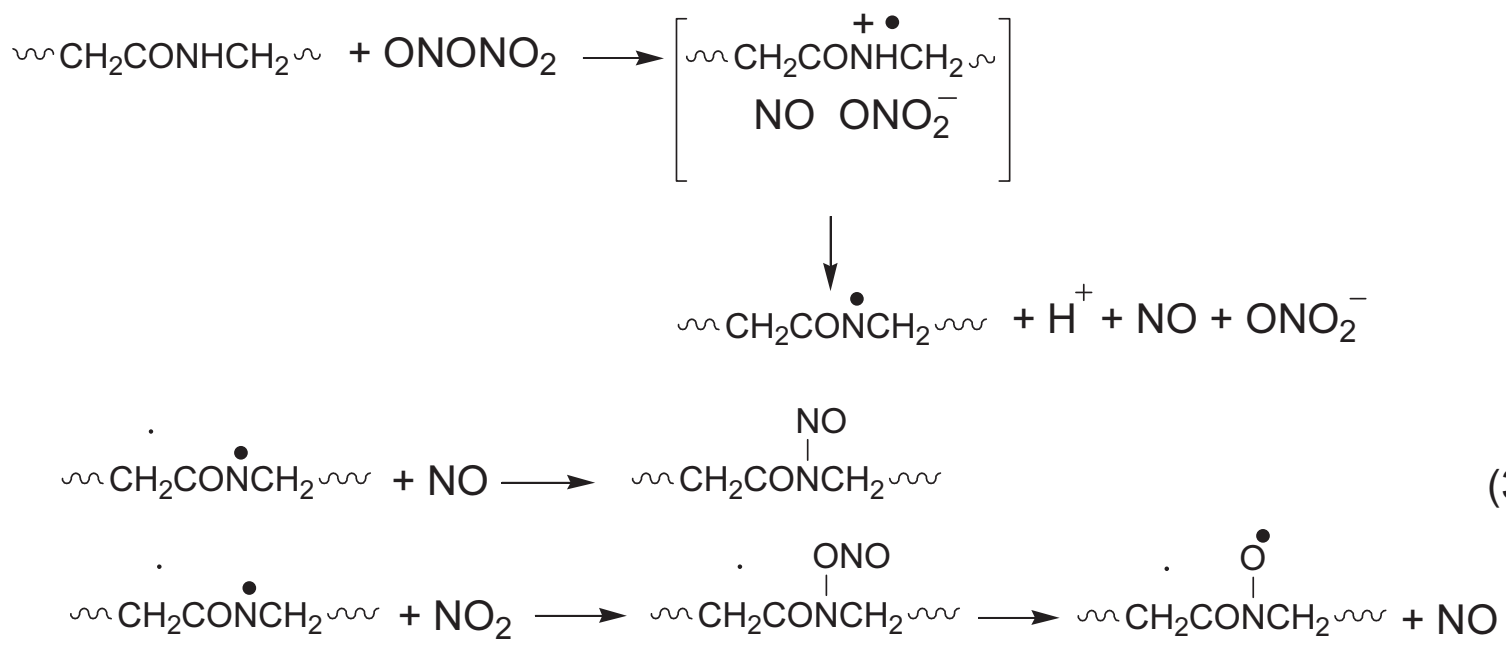

Reactions (35) at durable exposure lead to practically full disappearance of - $\mathrm{NH}$ - groups in macromolecules. Amidyl macroradicals leaving the "cage" are decomposed with breaking the main chain and can also be converted into $\mathrm{N}$-nitrite by recombination with the monomer form of $\mathrm{NO}_{2}$. The decomposition of $\mathrm{N}$-nitrites is registered in polycaproamide acylalkylaminoxyl

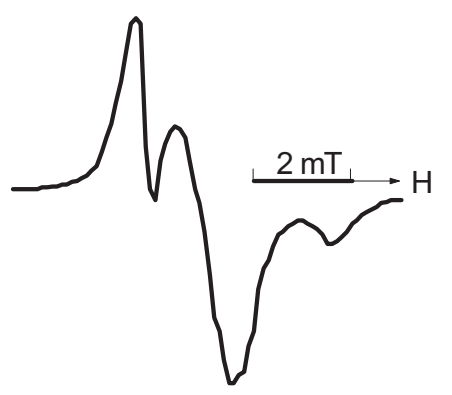

Fig. 11. ESR spectrum of polycaproamide after exposure to $\mathrm{NO}_{2}$ at $295 \mathrm{~K}$

The main free-radical products of AP (poly-mphenylene isophthalamide) exposure to $\mathrm{NO}_{2}$ are iminoxyl radicals of two isomeric forms [12]. At the initial stage of the AP exposure, the ESR spectrum shown in Fig. 13a is observed. It represents anisotropic triplet with $A^{\mathrm{N}}=(4.8 \pm 0.1) \mathrm{mT}, A_{\perp}^{\mathrm{N}}=(2.0024 \pm 0.0003)$ and $g_{\|}=(3.2 \pm 0.1) \mathrm{mT}, \quad g_{\perp}=(2.0047 \pm 0.0003)$. By its specific form and measured parameters, this signal macroradicals. The ESR spectrum of these radicals is shown in Fig. 11. It represents a triplet anisotropic signal with $A_{\mathrm{II}}^{\mathrm{N}}=1.94 \mathrm{mT}$ and $g_{\mathrm{II}}=2.003$. In IR spectra of polycaproamide exposed to nitrogen dioxide, stretch bands of $\mathrm{N}=\mathrm{O}$ in nitroso amide groups at 1504 and $1387 \mathrm{~cm}^{-1}$ are also observed (Fig. 12).

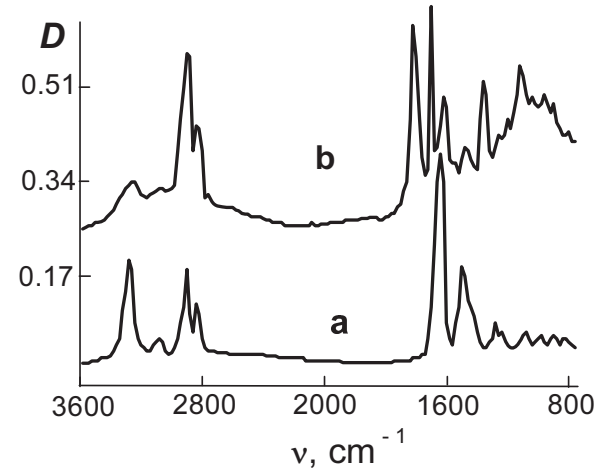

Fig. 12. IR spectra of original films of polycaproamide (a) and after exposure to $\mathrm{NO}_{2}$ (b)

corresponds to a spectrum of iminoxyl radicals (I) in a solid phase. At later stages (Fig. 13 b), a signal of the second iminoxyl radical (II) appears. The spectrum of radicals II is also anisotropic triplet but with other parameters: $A_{\|}^{\mathrm{N}}=(4.1 \pm 0.1) \mathrm{mT}, g_{\|}=(2.0024 \pm 0.0003)$ and $A_{\perp}^{\mathrm{N}}=(2.6 \pm 0.1) \mathrm{mT}, \quad g_{\perp}=(2.0050 \pm 0.0003)$. Based on the mechanisms $(29,30)$, the process of iminoxyl radical formation is represented schematically as follows: 
<smiles></smiles><smiles>CC(=O)Nc1cccc(N=C(C)C(C)C)c1</smiles>

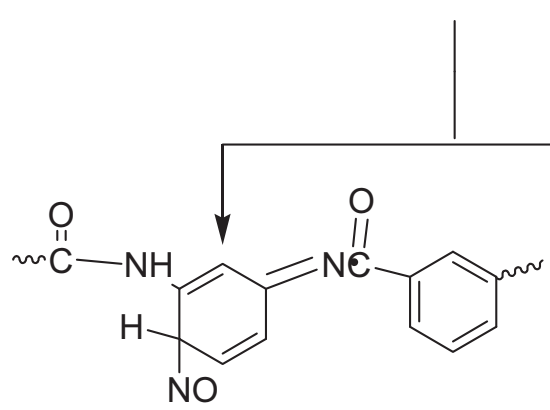

$\mathrm{NO} \mathrm{H}^{+} \quad \mathrm{ONO}_{2}^{-}$<smiles>CO/N=C1/C=CC(=NC(=O)c2cccc(C)c2)C=C1NC(C)=O</smiles>

I

Thus, the interaction of AP with $\mathrm{NO}_{2}$ by the ionradical mechanism is capable of initiating conversions of chemically inert phenyl rings into much more reactive cyclohexadiene groups.

\subsection{Conversion of nitrogen dioxide PD into NN under the influence of amide groups of macromolecules}

As indicated above, the equilibrium (32) should be shifted to PD in a gas phase due to the higher energy of $\mathrm{NN}$ in comparison with that for PD [33]. Nevertheless, the effective formation of stable radicals is observed in polyamides exposed to nitrogen dioxide by ion-radical mechanism. On this basis it is possible to suggest that the shift of equilibrium (32) to the formation of $\mathrm{NN}$ in polyamides is caused by specific donor-acceptor interaction of PD with amide groups which induce the conversion into $\mathrm{NN}$ and consequently the ion-radical process by the scheme (29). As the indicator of PD conversion into $\mathrm{NN}$, the dependence of the yield of oxyaminoxyl radicals $\left(\mathrm{R}_{\text {oxy }}\right)$ and iminoxyl radicals $\left(\mathrm{R}_{\mathrm{im}}\right)$ on the contents of AP (poly- $m$-phenylene isophthalamide) in the composites of AP with $p$-benzoquinone $(\mathrm{Q})$ has been used. As noted above, the formation of $R_{\text {oxy }}$ and $R_{\text {im }}$ is connected correspondingly with PD and NN. The results obtained are shown in Fig. 14. One can see from the figure, the concentration of radicals $R_{\text {oxy }}$ accumulated monotonously decreases with the increase of AP relative content, while concentrations of $\mathrm{R}_{\mathrm{im}}$ radicals vary within $10-20 \%$ of the average value, that is, within the accuracy of integration of ESR spectra. This fact indicates obvious dependence of the $R_{\text {oxy }}$ yield on the contents of polymers with amide groups in composites, suggesting that PD is converted under the influence of amide groups into $\mathrm{NN}$ 


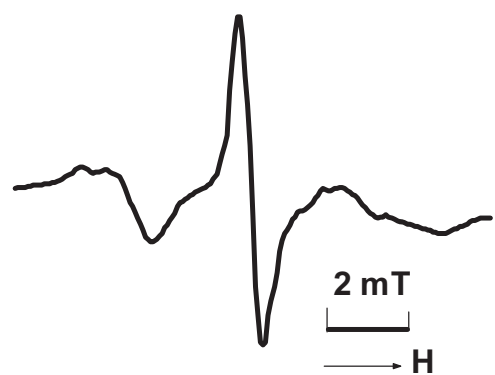

Fig. 13. ESR spectrum of AP after exposure to $\mathrm{NO}_{2}$ at $295 \mathrm{~K}$

that generates stable radicals $\mathrm{R}_{\mathrm{im}}$ in AP. It is significant that an appreciable decrease of the yield of $\mathrm{R}_{\text {oxy }}$ radicals was not observed in control experiments when polymers of other chemical structure, for example, acetyl cellulose were used in composites with Q. Therefore one can

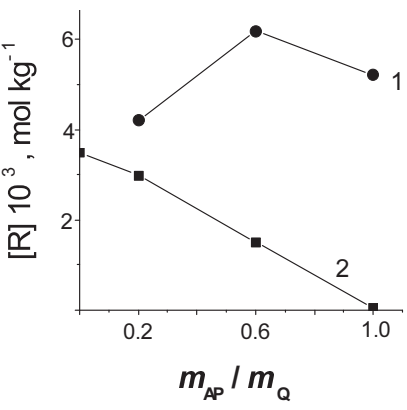

Fig. 14. Dependence of concentrations of $\mathrm{R}_{\mathrm{oxy}}$ (1) and $\mathrm{R}_{\mathrm{im}}(2)$ in $\mathrm{Q}+\mathrm{AP}$ after exposure to $\mathrm{NO}_{2}$ on weight ratio of $\mathrm{Q}$ and $\mathrm{AP}$

conclude that amide groups play special role in the $\mathrm{PD} \rightarrow \mathrm{NN}$ process.

The decrease of a relative yield of $\mathrm{R}_{\text {oxy }}$ radicals while adding polymers with amide groups to composites (Fig. 14) is apparent from the formal kinetic scheme:

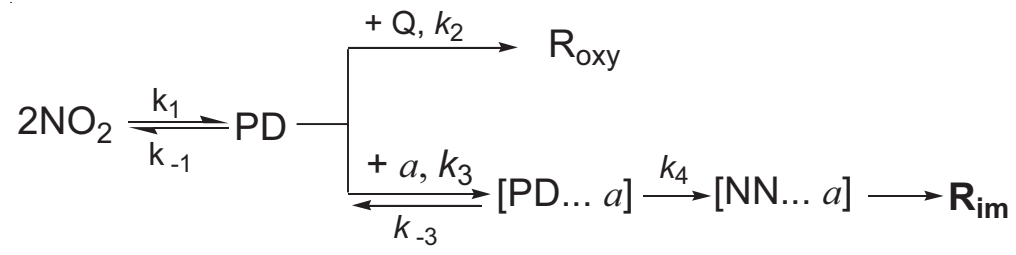

where $a$ is an amide group. Taking into

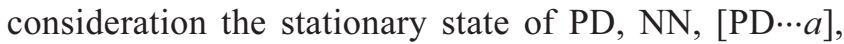
$[\mathrm{NN} \cdots a]$ concentrations, the following equations for rates of accumulation of radicals $\mathrm{R}_{\text {oxy }}$ and $\mathrm{R}_{\mathrm{im}}$ can be obtained:

$$
\frac{d[\mathrm{I}]}{d t}=\frac{k_{1} k_{2}[\mathrm{Q}]\left(k_{-3}+k_{4}\right)\left[\mathrm{NO}_{2}\right]^{2}}{\left(k_{-3}+k_{4}\right)\left(k_{-1}+k_{2}[\mathrm{Q}]+k_{3}[a]\right)-k_{-3} k_{3}[a]}
$$

$$
\frac{d[\mathrm{II}, \mathrm{III}]}{d t}=\frac{k_{1} k_{3} k_{4}[a]\left[\mathrm{NO}_{2}\right]^{2}}{\left(k_{-3}+k_{4}\right)\left(k_{-1}+k_{2}[\mathrm{Q}]+k_{3}[a]\right)-k_{-3} k_{3}[a]}
$$

where $\left[\mathrm{NO}_{2}\right]$ is the concentration of nitrogen dioxide in a gas phase, $[a]$ is the concentration of amide groups. These equations can be simplified if concentrations of amide groups in composites are comparatively high, and the conversion of PD into NN occurs rather effectively, that is $k_{3}[a]>>k_{-1}+k_{2}$. Then

$$
\begin{aligned}
& \frac{d\left[\mathrm{R}_{\text {oxy }}\right]}{d t}=\frac{k_{1} k_{2}\left(k_{-3}+k_{4}\right)\left[\mathrm{NO}_{2}\right]^{2}}{k_{3} k_{4}[a]} \\
& \frac{d\left[\mathrm{R}_{\text {in }}\right]}{d t}=k_{1}
\end{aligned}
$$

Thus the rate of accumulation of $\mathrm{R}_{\mathrm{im}}$ radicals is determined by $\left[\mathrm{NO}_{2}\right]$, and concentrations of these radicals accumulated on exposure to nitrogen dioxide do not depend appreciably on AP contents (Fig. 14, curve 2). In contrast, the yield of $\mathrm{R}_{\text {oxy }}$ decreases as the polyamide is added to composites and $[a]$ is increased. These diagram points are representative of competitive pathways for PD interactions with $\mathrm{Q}$ and amide groups.

\section{8. $A b$ initio calculations of energies for conversions of nitrogen dioxide dimmers}

For validating the mechanism proposed of the conversion of PD into $\mathrm{NN}$, the calculations of energy changes in the process of nitrogen dioxide interaction with the simplest amide (formamide) have been carried out within the framework of density functional theory by the Gaussian 98 program [47]. The B3LYP restricted method for closed and open shells was used. The aim of the calculations is to correlate energy consumptions for $\mathrm{PD} \rightarrow \mathrm{NN}$ with those for other stages of the radical generation process. The energies of the following states according to scheme (37) were calculated: 


$$
\begin{aligned}
& 2 \mathrm{NO}_{2}+\mathrm{NH}_{2} \mathrm{COH} \\
& \mathrm{O}_{2} \mathrm{~N}_{-} \mathrm{NO}_{2}+\mathrm{NH}_{2} \mathrm{COH} \\
& \mathrm{ONONO}_{2}+\mathrm{NH}_{2} \mathrm{COH} \\
& {\left[\mathrm{O}_{2} \mathrm{~N}_{-} \mathrm{NO}_{2} \cdots \mathrm{NH}_{2} \mathrm{COH}\right]} \\
& {\left[\mathrm{ONONO}_{2} \cdots \mathrm{NH}_{2} \mathrm{COH}\right]} \\
& \mathrm{NHCOH}^{\cdot} \mathrm{NO}+\mathrm{HNO}_{3} \\
& \mathrm{NH}_{2} \mathrm{CO}+\mathrm{NO}+\mathrm{HNO}_{3}+
\end{aligned}
$$

The geometry optimization of all structures was performed applying the basis set $6-31 \mathrm{G}(\mathrm{d}, \mathrm{p})$. The given process includes intermediate molecular complexes of PD and NN with formamide $(45,46)$. The changes of minimum energies are shown in Fig. 15. One can see the formation of PD from $\mathrm{NO}_{2}$ is energetically advantageous process [33], whereas $\mathrm{NN}$ is generated from $\mathrm{NO}_{2}$ in an endothermic reaction. The complexation of $\mathrm{PD}$ with formamide is accompanied by the release of energy: $\Delta E=28 \mathrm{~kJ} \cdot \mathrm{mol}^{-1}$. However, PD in the complex (45) is not capable of reacting with formamide and can leave only the reacting cage. At the same time, $\mathrm{PD}$ in the complex can be converted approximately with the same energy consumption into NN (46), which further reacts by the electron transfer reactions $(47,48)$ giving radicals, nitric oxide, nitric acid and significant release of energy $\left(44-57 \mathrm{~kJ} \cdot \mathrm{mol}^{-1}\right)$. Such sequence of transformations seems to be more efficient in comparison with a direct interaction of $\mathrm{NN}$ and formamide by state (44), as the energy of dimers in complexes (45) and (46) is lower than that of an initial state (42).

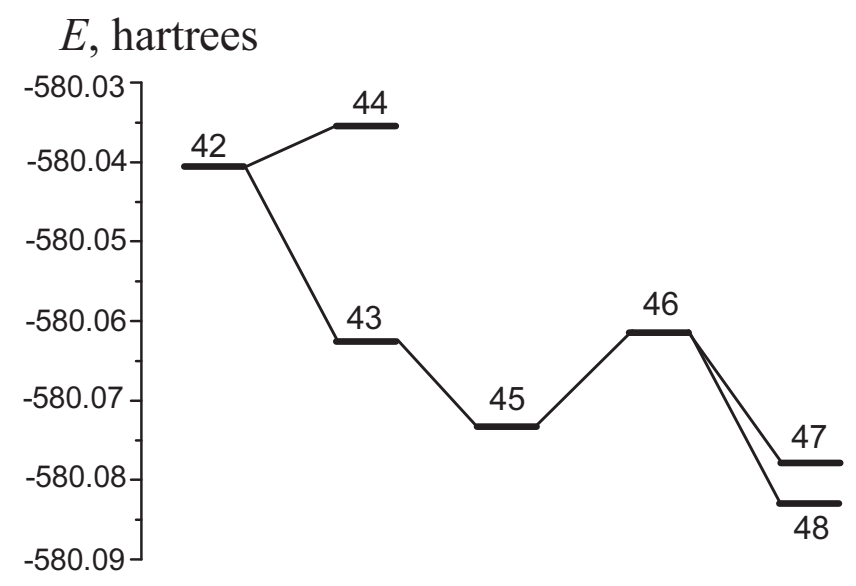

Fig. 15. Changes of minimum energies calculated for reactions of $\mathrm{NO}_{2}$ with formamide

\section{Conclusions}

Nitrogen oxides are the effective initiators of radical reactions for a number of polymers with formation of various molecular nitration products and stable nitrogencontaining radicals. Nitric oxide does not react directly, but it recombines with free radicals formed in polymers by UV photolysis or $\gamma$-radiolysis. The nitroso compounds formed in the subsequent reactions are converted into stable radicals. By this way, spin labels can be inserted even to chemically inert polyperfluoroalkanes. However, the chemical structure of macromolecules can be essentially changed in that case of rather hard conditions of radical generation. In this connection, nitrogen trioxide obtained by photolysis of the Ce (IV) nitrates is promising in application for spin labels synthesis. Under the action of visible and close UV light on these additives, the radicals and nitric oxide are formed simultaneously with transformation finally into spin labels. The light of such spectral composition does not cause undesirable side effects on macromolecules. Nitrogen dioxide is capable of interacting with the least strong $\mathrm{C}-\mathrm{H}$ and double $\mathrm{C}=\mathrm{C}$ bonds initiating thus radical reactions in the given system. The dimeric forms of nitrogen dioxide actively react by mechanism depending on the chemical structure of those forms. The dimers in the form of nitrosyl nitrate represent oxidizing agent initiating ion-radical reactions with the formation of stable nitrogen-containing radicals. Amide groups can induce a transition of energetically less capacious planar dimers of $\mathrm{NO}_{2}$ into nitrosyl nitrate. This specific ion-radical mechanism determines the high activity relative to $\mathrm{NO}_{2}$ even with such stable polymers as aromatic polyamides.

\section{References}

[1] Graham R. and Johnston H.: J. Phys. Chem., 1978, 82, 254.

[2] Johnston H. and Graham R.: Canad. J. Chem., 1974, 52, 1415.

[3] Stroud C., Madronich S., Atlas E., Ridley B., Flocke F. et al.: Atmospheric Environment, 2003, 37, 3351.

[4] Tong D., Kang D., Aneja V. and Ray J.: ibid., 2005, 39, 315.

[5] Titov A.: Tetrahedron, 1963, 19, 557.

[6] Topchiev A.: Nitrovanie uglevodorodov i drugih organicheskih soedinenij. Acad. of Sci. of the USSR, Moskva 1956.

[7] Novikov S., Shveyhgeymer G., Sevastyanova V.and Shlyapochnikov V.: [in:] Khimiya aliphaticheskih alicyclicheskih nitrosoedinenij. Khimiya, Moskva 1974.

[8] Pariiskii G., Gaponova I. and Davydov E.: Russ. Chem. Rev., 2000, 69, 985.

[9] Pariiskii G., Gaponova I., Davydov E. and Pokholok T.: [in:] Zaikov G., Buchachenko A., Ivanov V. (eds.), Aging of polymers, polymer blends and polymer composites. Nova Science Publishers, New York 2002.

[10] Vasserman A. and Kovarsky A.: Spin labels and spin probes in physical chemistry of polymers. Nauka, Moskva 1986.

[11] Gaponova I., Davydov E., Pariiskii G. and Pustoshny V.: Vysokomol. Soed. (A), 2001, 43, 98.

[12] Pokholok T., Gaponova I., Davydov E. and Pariiskii G., Polym. Degrad. Stability, 2006, 91, 2423.

[13] Bonner F. and Stedman G.: [in:] Feelish M. and Stamler J. (eds.), Methods in nitric oxide research. Wiley, Chichester 1996. [14] Ranby B. and Rabek J.: Photodegradation, photooxidation and photostabilization of polymers. Wiley, London 1975. 
[15] Park J. and Walton J.: J. Chem. Soc., Perkin Trans. 2, 1997, 2579 .

[16] Gaponova I., Pariiskii G. and Toptygin D.: Vysokomolek. Soed., 1988, 30, 262.

[17] Gaponova I., Pariiskii G. and Toptygin D.: Khimich. Fizika, 1997, 16, 49.

[18] Neta P. and Huie R.: J. Phys. Chem., 1986, 90, 4644.

[19] Vencatachalapathy B. and Ramamurthy R.: J. Photochem. Photobiology A: Chem., 1996, 93, 1.

[20] Japar S. and Niki H.: J. Phys. Chem., 1975, 79, 1629.

[21] Atkinson R., Plum C., Carter W., Winer A. and Pitts J.: J. Phys. Chem., 88, 1210.

[22] Itho O., Akiho S. and Iino M.: J. Org. Chem., 1989, 54, 2436.

[23] Pikaev A., Sibirskaya G., Shyrshov E., Glazunov P. and Spicyn V.: Dokl. Akad. Nauk SSSR, 1974, 215, 645.

[24] Hayon E. and Saito E.: J. Chem Phys., 1965, 43, 4314.

[25] Dagliotti L. and Hayon E.: J. Phys. Chem., 1967, 71, 3802.

[26] Glass P. and Martin T.: J. Am. Chem. Soc., 92, 5084.

[27] Wine P., Mauldin R. and Thorn R.: J. Phys. Chem., 1988, 92, 1156 .

[28] Davydov E., Afanas'eva E., Gaponova I. and Pariiskii G.: Org. Biomol. Chem., 2004, 2, 1339.

[29] Atkins P., Keen N. and Symons M.: J. Chem. Soc., 1962, 2873.

[30] Naghash H., Massah A. and Erfan A.: Eur. Polym. J., 2002, 38, 147.

[31] Jellinek H.: Ch. 9 [in:] Aspects of degradation and stabilization of polymers. Elsevier, New York 1978.

[32] Giamalva D., Kenion G. and Pryor W.: J. Am. Chem. Soc., 1987, 109, 7059.

[33] Golding P., Powell J. and Ridd J.: J. Chem. Soc., Perkin Trans. 2, 1996, 813.

[34] Gyor M., Rockenbauer A. and Tudos F.: Tetrahedron Lett., 1986, 27, 4795.

[35] Pokholok T. and Pariiskii G.: Vysokomolek. Soed. (A), 1977, 39, 1152.
[36] McKee M.: J. Am. Chem. Soc., 1995, 117, 1629.

[37] White E.: ibid., 1955, 77, 6008.

[38] Davydov E., Gaponova I., Pariiskii G. and Pokholok T.: Polym. Sci. (A), 2006, 48, 375.

[39] Feuer H.: The chemistry of the nitro and nitroso groups, Wiley, New York 1969.

[40] Davydov E., Gaponova I. and Pariiskii G.: J. Chem. Soc., Perkin Trans. 2, 2002, 1359.

[41] Gabr I. and Symons M.: J. Chem. Soc., Faraday Trans., 1996, 92, 1767.

[42] Greatorex D. and Kemp J.: J. Chem. Soc., Faraday Trans., 1972, 68, 121.

[43] Suzuki H., Iwaya M. and Mori T.: Tetrahedron Lett., 1997, 38, 5647 .

[44] Bellamy L.: The infra-red spectra of complex molecules. Methuen, London 1957.

[45] Bosch E. and Kochi J.: J. Org. Chem., 1994, 59, 3314.

[46] Bockman T., Karpinski Z., Sankararaman S. and Kochi J.: J. Am. Chem. Soc., 1992, 114, 1970.

[47] Frisch M., Trucks G., Schlegel H., Scuseria J. et al.: Gaussian 98, Gaussian Inc., Pitsburgh, PA 1998.

\section{ПОЛІМЕРИ В ЗАБРУДНЕНІЙ АТМОСФЕРІ. ВІЛЬНО-РАДИКАЛЬНІ ТАЙОННО-РАДИКАЛЬНІ ПЕРЕТВОРЕННЯ, ВИКЛИКАНІ ОКСИДАМИ АЗОТУ}

Анотація. Оксиди, діоксиди та триоксиди азоту разом з дімерами діоксиду азоту є реакиійноздатними ініціаторами радикальних перетворень макромолекул $i$ модифікуючими реагентами полімерів. Розглянуті основні стадї̈ механізму інічіювання, який визначає склад молекулярних і радикальних продуктів в полімерах, викликане оксидами азоту.

Ключові слова: оксид азоту, полімер, реакція, радикал, ЕПР-спектр 